\title{
Museu virtual do corpo humano: ludicidade no ensino de Ciências Morfológicas
}

\section{Tatiana Montanari ${ }^{1}$, Eliane de Oliveira Borges $^{2}$, Ismael Krüger Pescke ${ }^{3}$}

${ }^{1}$ Professora associada do Departamento de Ciências Morfológicas, ICBS, UFRGS t.montanari@bol.com.br

${ }^{2}$ Especialista em Informática na Educação, CINTED, UFRGS; técnica-administrativa do Departamento de Fisiologia, ICBS, UFRGS - elianeoborges@gmail.com

${ }^{3}$ Graduando de Ciências Biológicas, UFRGS; Bolsista SEAD ismaelkp.bio@gmail.com

Resumo: A criação do Museu virtual do corpo humano visa promover de forma dinâmica a compreensão dos constituintes do corpo humano e de seu desenvolvimento. Espera-se que o aluno-internauta se familiarize com conceitos da área morfológica; estruture de forma correta o pensamento sobre o todo e as partes no que se refere à organização do corpo humano. $\mathrm{O}$ ambiente virtual de aprendizagem foi publicado na página institucional: http://www.ufrgs.br/museuvirtual. A navegação foi construída com o programa Adobe Dreamweaver. As exposições Conhecendo a célula, Conhecendo o corpo humano e $O$ Surgimento da vida consistem de vídeos com imagens de células, tecidos e órgãos, obtidas em microscopia de luz e eletrônica e animações sobre os sistemas, confeccionadas com o Adobe Illustrator. Além do acervo permanente, foi proposto um espaço virtual para divulgação de trabalhos de interesse clínico na área morfológica. No Espaço kids, há jogos sobre o corpo humano criados com o software Adobe Captivate. Com uma proposta lúdica, mas com informação qualificada, espera-se contribuir para a qualificação do ensino das Ciências Morfológicas.

Palavras-chave: histologia; embriologia; corpo humano; ambiente virtual de aprendizagem; educação a distância.

\section{Virtual museum of the human body: playfulness in the teaching of Morphological Sciences}

\begin{abstract}
The creation of the Virtual museum of the human body aims promoting the comprehension of the human body's constituents and of its development; the familiarization with concepts of the morphological area and the structuring of thought about the whole and the parts in what concerns the organization of the human body. The virtual learning environment was published in the institutional page: http://www.ufrgs.br/museuvirtual. Web browsing was made with Adobe Dreamweaver software. At the Knowing the cell, Knowing the human body and Emergence of life expositions there are videos with images of cells, tissues and organs, obtained by light and electron microscopy and animations about the systems made by Adobe Illustrator. Besides permanent expositions there is a virtual space for exhibiting research of clinic interest on morphological field. At Kids space there are games about the human body, created by Adobe Captivate software. Because playful character and qualified information of this virtual resource, we aim contributing to improve Morphological teaching.
\end{abstract}

Keywords: histology; embryology; human body; virtual learning environment; elearning. 


\section{INTRODUÇÃO}

As Ciências Morfológicas constituem uma área do conhecimento que abrange as disciplinas Biologia Celular, Histologia, Anatomia e Embriologia. A Biologia Celular investiga a célula, menor unidade estrutural e funcional do ser vivo, e os seus constituintes; a Histologia estuda os tecidos e os órgãos numa abordagem microscópica; a Anatomia realiza o estudo macroscópico dos órgãos do corpo, e a Embriologia trata do desenvolvimento do ser, desde a formação dos gametas até o nascimento (Carvalho \& Recco-Pimentel, 2013; Montanari, 2013; Carlson, 2014; Lowe \& Anderson, 2015; Montanari, 2016a; Montanari, 2016b; Montanari, 2016c; Ross \& Pawlina, 2016). Essas disciplinas são ministradas no ensino superior para vários cursos das Ciências Biológicas e da Saúde, e seu conteúdo é inserido nas disciplinas de Ciências e de Biologia do ensino fundamental e médio.

$\mathrm{Na}$ área morfológica, como sugere o seu nome, a informação visual é de suma importância. A maior parte desse conhecimento foi construída com a observação de células isoladas ou em cortes de tecidos ou órgãos ao microscópio de luz e ao microscópio eletrônico (Carvalho \& Recco-Pimentel, 2013; Alberts et al., 2015; Lowe \& Anderson, 2015; Montanari, 2016a; Montanari, 2016b; Montanari, 2016c; Ross \& Pawlina, 2016). No seu ensino, as atividades práticas com manipulação de peças macroscópicas e observação de preparados histológicos são fundamentais. Entretanto as constantes reformas curriculares têm reduzido a carga horária dessas disciplinas, em especial de aulas práticas. As ferramentas de educação a distância são uma alternativa para complementar o ensino presencial e otimizar o tempo do aluno e do professor dedicado ao conteúdo (Carlson, 2002; Heidger et al., 2002; Samar \& Avila, 2007; Ferreira \& Kempinas, 2010; Ferreira, 2011; Santa-Rosa \& Struchiner, 2011; Montanari, 2013; Montanari, 2016a; Montanari, 2016b; Montanari, 2016c; Montanari, 2016d).

A criação do Museu virtual do corpo humano tem por objetivo promover de forma dinâmica, através de vídeos, animações e jogos sérios, a compreensão dos constituintes do corpo humano e do desenvolvimento do indivíduo, desde a produção dos gametas e do seu encontro no processo de fertilização até o período embrionário e fetal; divulgar o acervo das disciplinas de Biologia Celular, Histologia e Embriologia e dos projetos de pesquisa relacionados à área, e contribuir para a qualificação do ensino das Ciências Morfológicas. Espera-se atingir como público-alvo alunos e professores do ensino fundamental, médio e superior, bem como internautas leigos interessados no assunto.

\section{METODOLOGIA}

A concepção pedagógica do projeto foi fundamentada nos estudos epistemológicos de Piaget $(1976 ; 1998)$, os quais descrevem que o conhecimento é derivado da ação, construído na interação do sujeito com o objeto, em um processo de transformação deste; a assimilação é uma reestruturação, uma reinvenção e demanda trabalho pessoal e, portanto, necessita interesse e esforço sistemático do aluno. Assim, a iniciativa pessoal e a interatividade foram referenciais para desenvolver o recurso digital, utilizando o software Adobe Dreamweaver para criar uma navegação hipertextual amigável e interativa. Para obter uma linguagem multimídia, decidiu-se utilizar, como principal recurso de apresentação do conteúdo, vídeos ilustrados com animações, acompanhados de narração explicativa. 
O menu apresenta três exposições: "Conhecendo a célula", "Conhecendo o corpo humano" e "O surgimento da vida", que exibem vídeos sobre o conteúdo. Eles foram realizados com a associação de fotografias, animações e áudio pelo software Adobe After effects. As fotografias são de células e tecidos dos diferentes órgãos, observados ao microscópio de luz (fotomicrografias) ou eletrônico (eletromicrografias); embriões de codorna foram fotografados ao microscópio de luz, embriões e fetos humanos, macroscopicamente. O material é proveniente de trabalhos de pesquisa e da coleção das disciplinas de Biologia celular, Histologia e de Embriologia. Em substituição a peças anatômicas, foram elaboradas ilustrações com o software Adobe Illustrator. A narração procurou evidenciar as características morfológicas e a relação entre a estrutura e a atividade funcional. Após a sua edição, os filmes foram exportados com a extensão AVI e, no programa Adobe Encoder, foram passados para a extensão FLV (Montanari \& Borges, 2012). Uma ultrassonografia gestacional também foi disponibilizada na exposição "O surgimento da vida".

Além do acervo permanente dessas exposições, foi proposto um espaço virtual para exibição de trabalhos da área e de interesse clínico. O evento temático escolhido inicialmente foi "Saúde da mulher". Ao acessar o ícone respectivo, há uma coleção de apresentações elaboradas em Microsoft PowerPoint pelas monitoras da disciplina de Embriologia e pelas orientadas de pesquisa do Laboratório de Biologia da Reprodução.

Há o "Espaço kids", uma brinquedoteca virtual, com jogos desenvolvidos com o programa Adobe Captivate. O jogo "Conhecendo o corpo humano" aborda os sistemas do corpo humano, através do posicionamento dos órgãos pelo arraste com o mouse para o corpo de uma menina (Yasmin) e de um menino (Yago). O desenho das personagens foi inspirado nos traços de mangá, enquanto a ação da atividade nos jogos infantis sobre vestuário e acessórios. O quebra-cabeça "Raio- $X$ " foi desenvolvido a partir de radiografias do esqueleto. "Floresta mágica, um jogo sobre digestão" tem como personagens as bruxinhas Oxíntica e Zimogênica (nome das células do estômago) que, no seu caldeirão, preparam o suco gástrico. Em "Varrendo a poeira, o sistema respiratório", as células ciliadas e as células caliciformes do epitélio respiratório são personificadas.

O contador de acesso Widgetcontador permite acompanhar o número de visitantes e a sua distribuição geográfica.

\section{RESULTADOS E DISCUSSÃO}

O Museu virtual do corpo humano (http://www.ufrgs.br/museuvirtual) é um ambiente virtual para o ensino e a aprendizagem das disciplinas de Ciências Morfológicas: Biologia celular, Histologia e Embriologia. Na interação com os elementos do Museu, espera-se que o aluno-internauta se familiarize com conceitos típicos da área morfológica; estruture de forma correta o pensamento sobre o todo e as partes no que se refere à organização do corpo humano, e compreenda o desenvolvimento humano.

O menu de navegação apresenta as exposições: "Conhecendo a célula", "Conhecendo o corpo humano" e "O surgimento da vida". Na tela inicial, há ainda os ícones "Eventos temáticos - Saúde da mulher" e "Espaço kids" (Figura 1). 

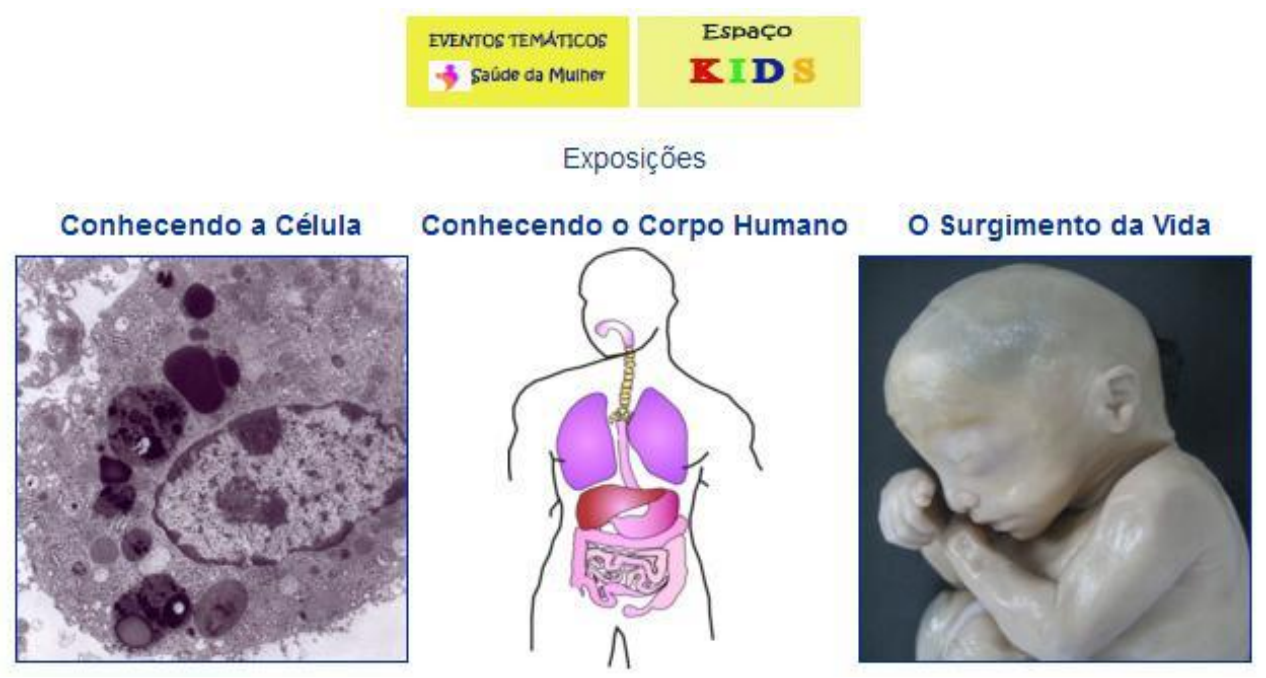

Figura 1 - Tela inicial do ambiente virtual.

O visitante-internauta, ao clicar na imagem da exposição "Conhecendo a célula", acessa um vídeo com áudio sobre os diversos tipos celulares, sua morfologia, função e localização. Ele é ilustrado com fotomicrografias das células de diferentes tecidos e órgãos e eletromicrografias das organelas para explicar a constituição da célula (Figura 2). Em "Conhecendo o corpo humano", o visitante acessa os filmes sobre os Sistemas respiratório, digestório e urinário, confeccionados com ilustrações e animações realizadas com o Adobe Illustrator e imagens ao microscópio de luz ou eletrônico dos órgãos, sendo abordadas as suas características morfológicas e atividade funcional (Figura 3). Na exposição "O surgimento da vida" há um vídeo narrado sobre o desenvolvimento do ser humano desde a produção e a fertilização dos gametas até o período embrionário e fetal e uma ultrassonografia fetal.
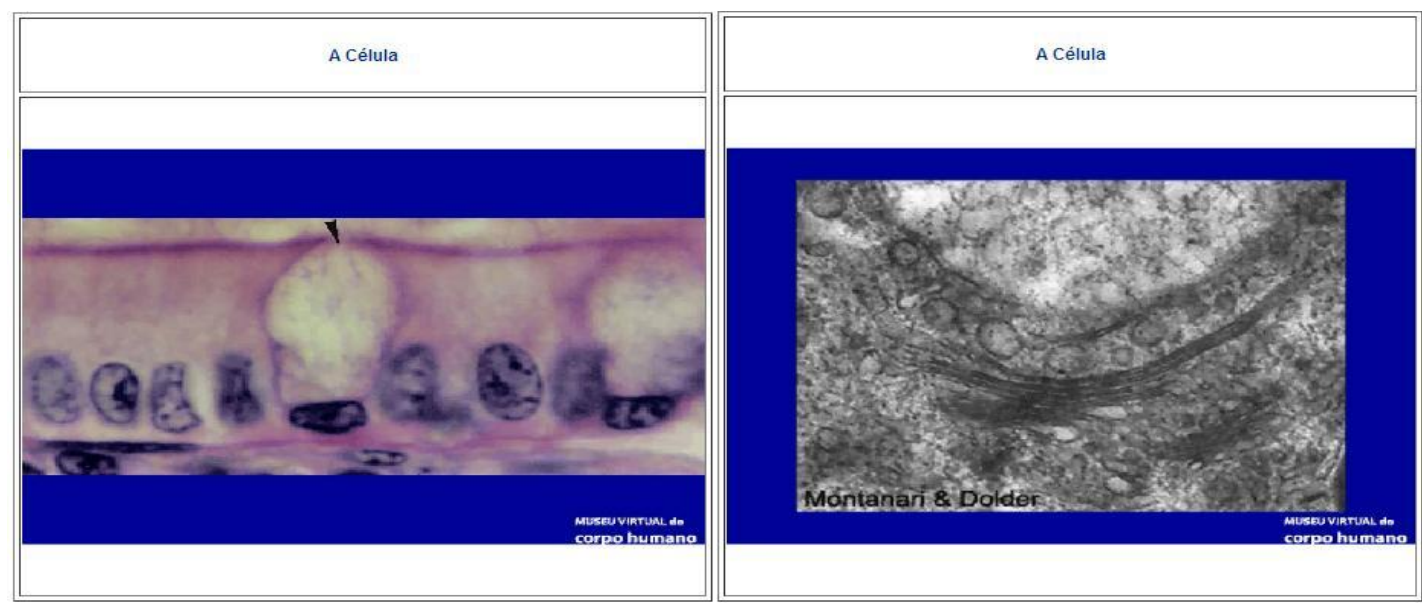

Figura 2 - Do vídeo "Conhecendo a célula": fotomicrografia do epitélio intestinal, apontando a célula caliciforme e eletromicrografia do complexo de Golgi, organela proeminente nessa célula. 


CINTED-UFRGS Novas Tecnologias na Educação
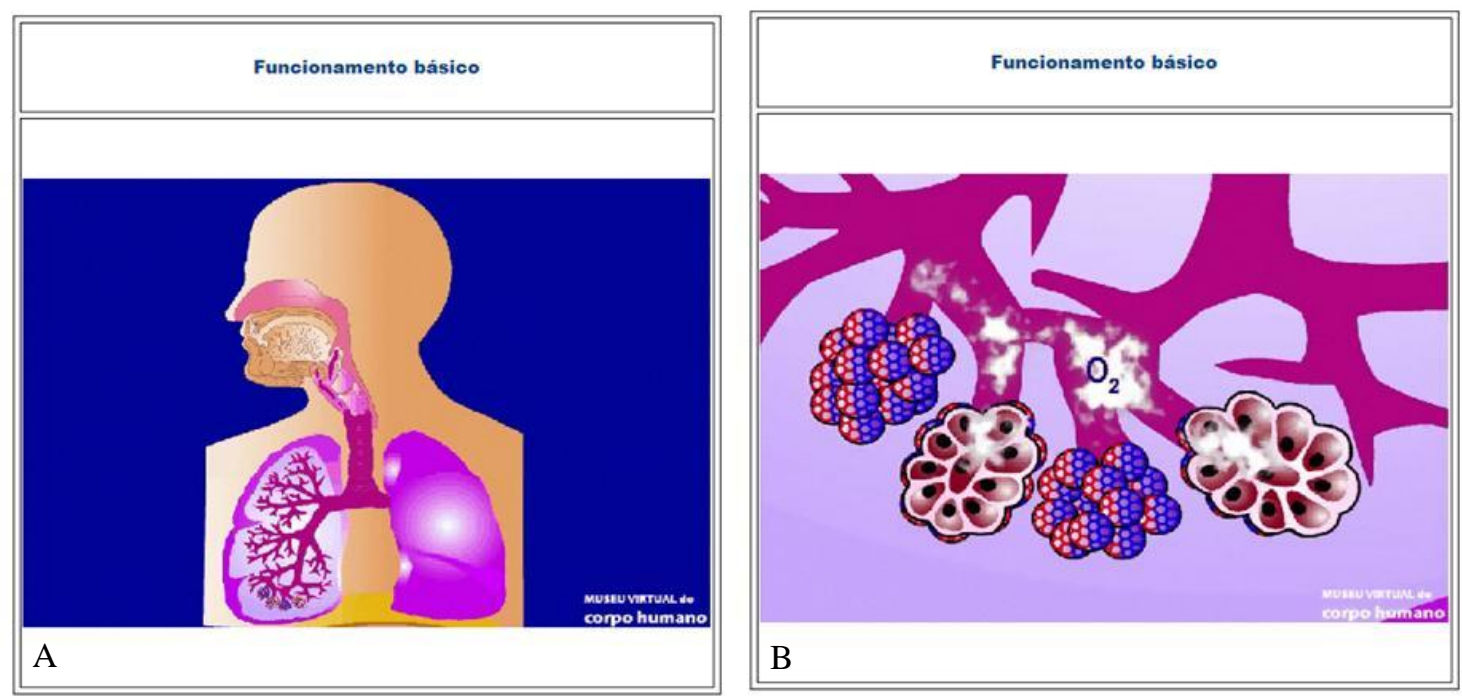

Figura 3 - Ilustrações da animação sobre "Sistema respiratório" da seção "Conhecendo o corpo humano".

A informação visual é essencial para a compreensão do conteúdo das Ciências Morfológicas, como sugerido na sua denominação. Imagens a olho nu ou em microscopia de luz ou eletrônica construíram (e constroem) o conhecimento dessa área. A visão é o sentido mais desenvolvido em humanos e é importante na aprendizagem, permitindo a coleta e o processamento de informações do ambiente a partir das quais são tomadas decisões e formulados conceitos. A linguagem visual promove a compreensão de conceitos abstratos pela conversão em imagens mentalmente manipuladas. A retenção do conteúdo como memória de longo prazo é facilitada pela combinação de estímulos visuais e verbais, como em filmes, vídeos e animações acopladas a uma narração. As atividades multimídias, resultantes da combinação de texto, imagens, vídeo, som e animação, permitem ainda a repetição, estimulam a exploração pelo estudante, favorecem a compreensão de processos visuais complexos e acomodam-se aos vários estilos de aprendizagem (Mayer \& Gallini, 1990; Heyden, 2004; Stith, 2004; McClean et al., 2005).

Além do acervo permanente das seções "Conhecendo a célula", "Conhecendo o corpo humano" e o "Surgimento da vida", foi proposto um espaço virtual para divulgação de trabalhos de interesse clínico na área morfológica, aproximando o saber científico da comunidade acadêmica e do público em geral. O tema escolhido foi "Saúde da mulher", com enfoque na reprodução. Apresentações em PowerPoint abordam o risco de infecções, como a rubéola e a toxoplasmose, e do consumo de álcool, complexos emagrecedores e plantas medicinais por mulheres em idade reprodutiva, tendo em vista o possível dano ao desenvolvimento embrionário e fetal (Figura 4). 


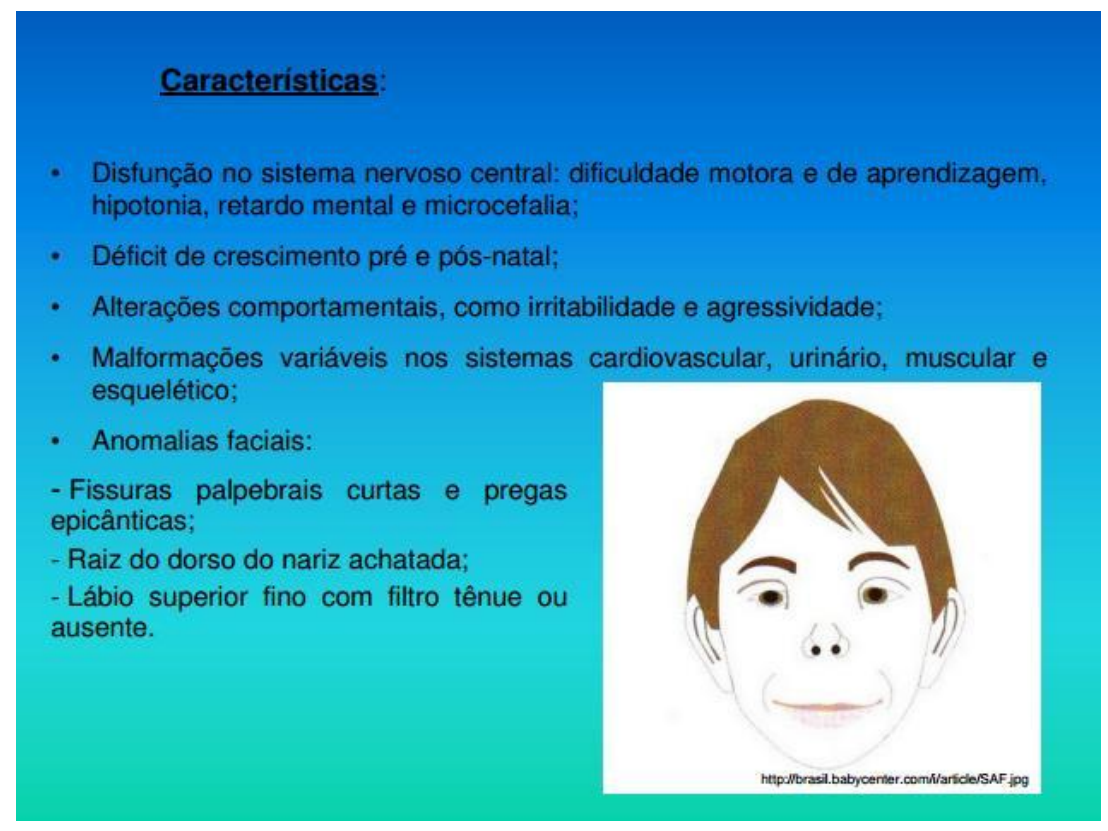

Figura 4 - Tela da apresentação sobre Síndrome do álcool fetal em "Eventos temáticos - Saúde da mulher".

O "Espaço kids" é uma sala de visitação para o público infantil brincar aprendendo. O jogo "Conhecendo o corpo humano com Yasmin e Yago" aborda a localização e a função dos órgãos do corpo humano; ambos sexos foram ilustrados para evidenciar que não há diferença no seu posicionamento (Figura 5). O quebra-cabeça "Raio-X" permite o conhecimento do interior do corpo a partir de imagens reais, as radiografias, tornando lúdico um elemento de diagnóstico clínico (Figura 6), e propõe para discussão questões cotidianas das crianças, como o uso de mochila pesada e a má postura e seu impacto na coluna vertebral. Em "Floresta mágica, um jogo sobre digestão", as bruxinhas Zimogênica e Oxíntica, de vestido roxo e rosa (cores que correspondem à coloração das células do estômago com Hematoxilina e Eosina), preparam o suco gástrico no caldeirão de magias, com enzimas e ácido clorídrico. No jogo "Varrendo a poeira, o sistema respiratório", são personificadas as células caliciformes e as células ciliadas, com traços que lembram a sua morfologia; elas realizam tarefas relacionadas à sua atividade funcional, como aprisionar as partículas de poeira e varrê-las para fora do trato respiratório; o prejuízo do fumo na função dessas células também é abordado como forma de prevenção. Nos jogos sobre o Sistema digestório e o Sistema respiratório, pretende-se a interação da criança com os personagens-células, a fim da compreensão lúdica da função desses sistemas. Os jogos serão testados e avaliados com alunos do ensino fundamental de faixa etária apropriada, a fim da adequação na navegação e na abordagem do tema. 


CINTED-UFRGS Novas Tecnologias na Educação
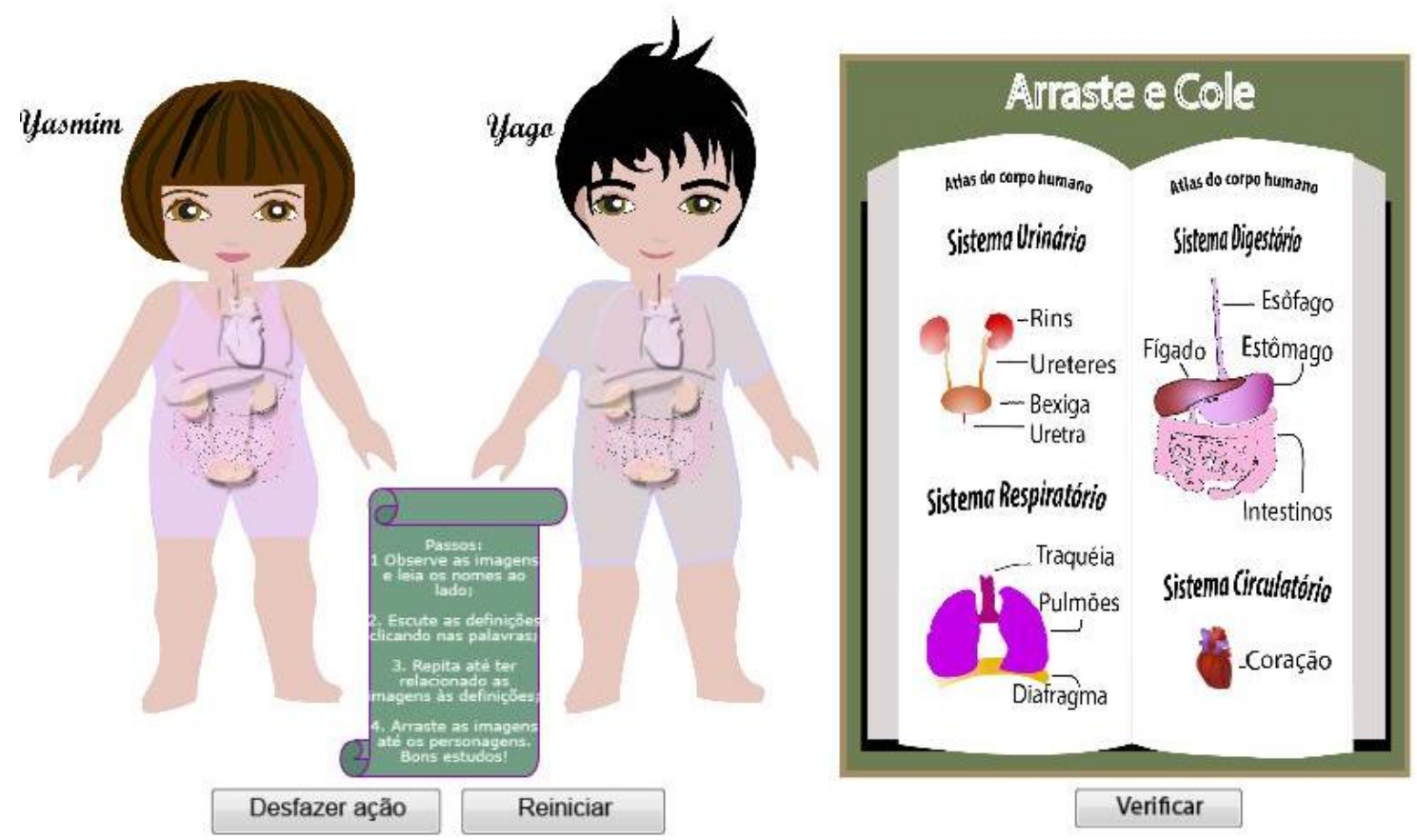

Figura 5 - Jogo "Conhecendo o corpo humano" exibido no "Espaço kids".

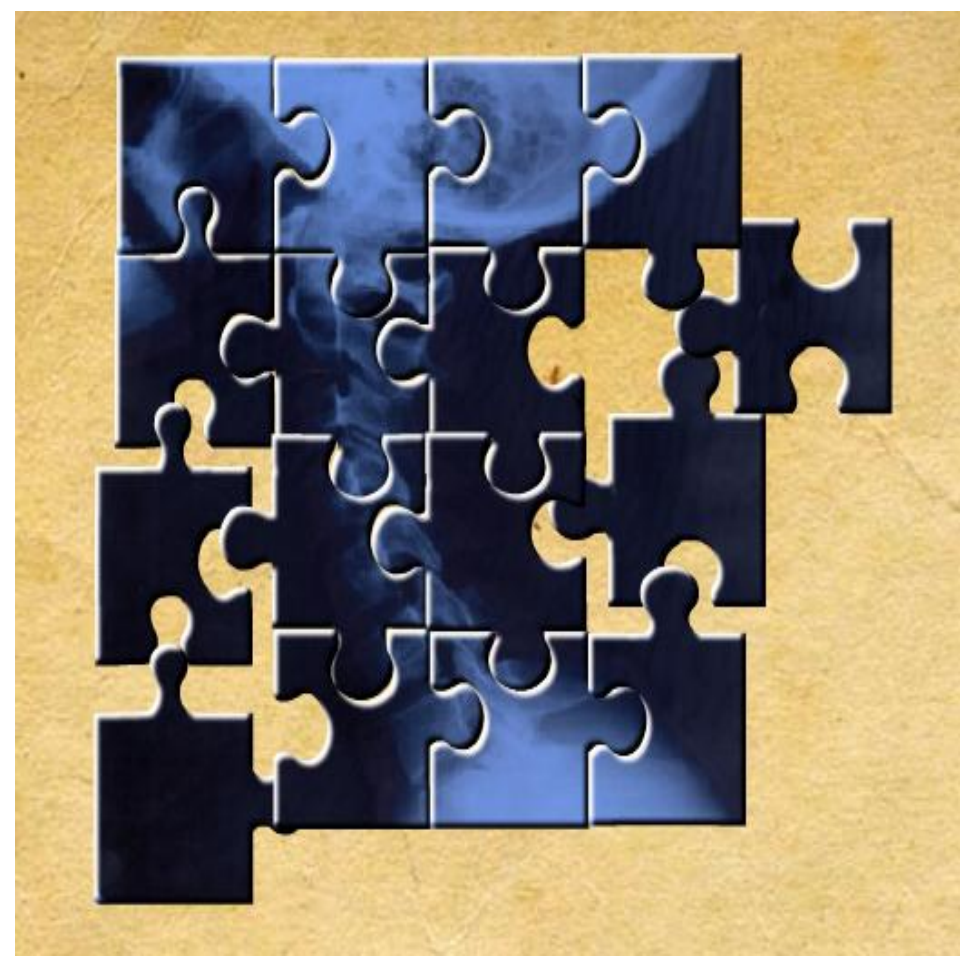

Figura 6 - Tela do quebra-cabeça "Raio-X".

O uso de plataformas educacionais virtuais tem mostrado resultados positivos no meio acadêmico ao cumprir seu propósito de fomentar a construção ativa do conhecimento e otimizar o tempo do aluno e do professor dedicado ao conteúdo, indicando a sua aplicabilidade como recurso pedagógico alternativo que suplementa o ensino presencial (Heidger et al., 2002; Samar \& Avila, 2007; Ferreira \& Kempinas, 2010; Ferreira, 2011; Santa-Rosa \& Struchiner, 2011; Montanari, 2016). 
Espera-se que a elaboração desse ambiente virtual tenha contribuído para a difusão das Ciências Morfológicas e propiciado de forma atraente a compreensão do desenvolvimento do indivíduo e dos constituintes do corpo humano.

\section{CONCLUSÕES}

A criação do Museu virtual do corpo humano (http://www.ufrgs.br/museuvirtual) visa difundir o conhecimento das Ciências Morfológicas e promover a compreensão dos componentes do corpo humano: sistemas, tecidos e células, sob os aspectos estruturais e funcionais. Para a sua navegação, foi usado o software Adobe Dreamweaver. Vídeos com animações foram realizados com os softwares Adobe After effects e Illustrator. É apresentado o acervo de imagens macroscópicas e obtidas em microscopia de luz e eletrônica, utilizadas nas disciplinas de Biologia celular, Histologia e Anatomia. Há um espaço virtual para exibição de apresentações de interesse clínico na área morfológica. Foram desenvolvidos jogos para o público infantil sobre os sistemas utilizando o Adobe Captivate. Este museu virtual tem uma concepção original, com um efeito visual lúdico que permite o acesso inclusive por adolescentes e crianças. Espera-se que a sua elaboração contribua para a qualificação do ensino das Ciências Morfológicas.

\section{AGRADECIMENTOS}

À Secretaria de Educação a Distância (SEAD), pela bolsa para desenvolvimento de objeto de aprendizagem para Ismael Krüger Pescke (Edital 024, 2017).

\section{REFERÊNCIAS BIBLIOGRÁFICAS}

ALBERTS, B.; JOHNSON, A.; LEWIS, J.; MORGAN, D.; RAFF, M.; ROBERTS, K.; WALTER, P. Molecular Biology of the Cell. 6.ed. New York: Garland Science, 2015. p. 529, 554, 558.

CARLSON, B. M. Embryology in the medical curriculum. The Anatomical Record, v. 269, n. 2, p. 89-98, 2002.

CARLSON, B. M. Human Embryology and Developmental Biology. 5.ed. Philadelphia: Elsevier Saunders, 2014. p. 2, 453.

CARVALHO, H. F.; RECCO-PIMENTEL, S. A Célula. 3.ed. Barueri: Manole, 2013. p. $1-2$.

FERREIRA, A. S. S. B. S.; KEMPINAS, W. D. G. Avaliação de um ambiente virtual de ensino de apoio à educação presencial em curso de graduação em Biologia. In: CONGRESSO INTERNACIONAL DE EDUCAÇÃO A DISTÂNCIA. 16., 2010, Foz do Iguaçu. Anais. Foz do Iguaçu: Associação Brasileira de Educação a Distância, 2010. Disponível em:

<http://www.abed.org.br/congresso2010/cd/2152010154536.pdf>. Acesso em: 09 set. 2017.

FERREIRA, A. S. S. B. S. Elaboração e avaliação de um ambiente virtual para o ensino/aprendizagem de Embriologia. Botucatu: UNESP, 2011. 90 p. Tese de Doutorado. Disponível em:

<http://www.ibb.unesp.br/posgrad/teses/bga_do_2011_ana_ferreira.pdf>. Acesso em: 09 set. 2017. 
HEIDGER Jr., P. M.; DEE, F.; CONSOER, D.; LEAVEN, T.; DUCAN, J.; KREITER, C. Integrated approach to teaching and testing in Histology with real and virtual imaging. The Anatomical Record, v. 269, p.107-112, 2002. Disponível em: <http://onlinelibrary.wiley.com/doi/10.1002/ar.10078/epdf>. Acesso em: 4 maio 2017.

HEYDEN, R. J. Approaches to Cell Biology: developing educational multimedia. Cell Biology Education, v. 3, p. 93-98, 2004. Disponível em:

<https://www.ncbi.nlm.nih.gov/pmc/articles/PMC437640/pdf/03-08-0009_p093.pdf>.

Acesso em: 09 set. 2017.

LOWE, J. S.; ANDERSON, P. G. Stevens \& Lowe's Human Histology. 4.ed. Elsevier Mosby, 2015. p. 1-5

MAYER, R. E.; GALLINI, J. K. When is an illustration worth ten thousand words? Journal of Educational Psychology, v. 82, n. 4, p. 715-726, 1990. Disponível em: $<$ http://citeseerx.ist.psu.edu/viewdoc/download?doi=10.1.1.462.2856\&rep=rep1\&type= pdf>. Acesso em: 14 dez. 2017.

MCCLEAN, P.; JOHNSON, C.; ROGERS, R.; DANIELS, L.; REBER, J.; SLATOR, B. M.; TERPSTRA, J.; WHITE, A. Molecular and cellular Biology animations: development and impact on student learning. Cell Biology Education, v. 4, p. 169-179, 2005. Disponível em:

<https://www.ncbi.nlm.nih.gov/pmc/articles/PMC1103718/pdf/i1536-7509-4-2169.pdf>. Acesso em: 09 set 2017.

MONTANARI, T. Embriologia: texto, atlas e roteiro de aulas práticas. Porto Alegre: Ed. da autora, 2013. prefácio. Disponível em: 〈http://www.ufrgs.br/livrodeembrio>. Acesso em: 14 dez. 2017.

MONTANARI, T. Atlas de Biologia celular e tecidual. Porto Alegre: Ed. da autora, 2016a. prefácio. Disponível em: <http://www.ufrgs.br/atlasbiocel>. Acesso em: $14 \mathrm{dez}$. 2017.

MONTANARI, T. auladehisto. Porto Alegre: Ed. da autora, 2016b. p. 3-4. Disponível em: 〈https://www.ufrgs.br/auladehisto>. Acesso em: 14 dez. 2017.

MONTANARI, T. Histologia: texto, atlas e roteiro de aulas práticas. 3.ed. Porto Alegre: Ed. da autora, 2016c. p. 1-8, 29. Disponível em:

<http://www.ufrgs.br/livrodehisto>. Acesso em: 14 dez. 2017.

MONTANARI, T. Recursos virtuais para o ensino presencial e remoto de Histologia. RENOTE - Revista Novas Tecnologias na Educação, v. 14, n. 2, p. 1-12. 2016d. Disponível em: <http://dx.doi.org/10.22456/1679-1916.70635>. Acesso em: 02 dez. 2017.

MONTANARI, T.; BORGES, E. O. Museu virtual do corpo humano: ambiente virtual de aprendizagem para o ensino de Ciências Morfológicas. RENOTE Revista Novas Tecnologias na Educação, v. 10, n. 2, p. 1-11, 2012. Disponível em: <http://seer.ufrgs.br/index.php/renote/article/view/36401>. Acesso em: 13 set. 2017.

PIAGET, J. Psicologia e Pedagogia. 4.ed. Rio de Janeiro: Forense Universitária, 1976. p. $37,48$.

PIAGET, J. Sobre Pedagogia. São Paulo: Casa do Psicólogo, 1998. p. 138-139, 149.

ROSS, M. H.; PAWLINA, W. Histologia: texto e atlas, correlações com Biologia celular e molecular. 7.ed. Rio de Janeiro: Guanabara Koogan, 2016. p. 1-23, 73, 98, 105.

SAMAR, M. E.; AVILA, R. E. Materiales instruccionales en la enseñanza virtual de la histologia y embriologia humana. In: CONGRESSO VIRTUAL 
HISPANOAMERICANO de ANATOMÍA PATOLÓGICA. 9., e CONGRESSO DE PREPARACIONES VIRTUALES POR INTERNET. 2., 2007, Ciudad Real. Anais. Ciudad Real: Universidad de Castilla La Mancha y Complejo Hospitalario de Ciudad Real. 2007. Disponível em:

$<\mathrm{http}: / /$ www.conganat.org/9congreso/trabajo.asp?id_trabajo=688\&tipo=2>. Acesso em: 09 set. 2017.

SANTA-ROSA, J. G.; STRUCHINER, M. Tecnologia educacional no contexto do ensino de Histologia: pesquisa e desenvolvimento de um ambiente virtual de ensino e aprendizagem. Revista Brasileira de Educação Médica, v. 35, n. 2, p. 289-298, 2011. Disponível em: <http://www.scielo.br/pdf/rbem/v35n2/20.pdf>. Acesso em: 09 set. 2017.

STITH, B. J. Use of animation in teaching Cell biology. Cell Biology Education, v. 3, p. 181-188, 2004. 